\title{
Diurnal patterns of oral glucose tolerance in diabetics
}

\author{
C. H. WALSH \\ M.D., M.R.C.P.
}

\author{
A. D. WRIGHT \\ M.B., M.R.C.P.
}

\section{Diabetic Clinic, The General Hospital, Birmingham}

\begin{abstract}
Summary
Oral glucose tolerance tests were performed in the morning and afternoon in twenty newly diagnosed untreated diabetic patients. Fasting blood glucose levels were significantly higher in the morning than in the afternoon. Blood glucose values after glucose ingestion also tended to be higher in the morning than in the afternoon. This pattern, however, was most marked for the patients with the greatest degrees of hyperglycaemia. It was also more evident in females than males. Serum insulin values did not differ significantly in the morning and afternoon.
\end{abstract}

\section{Introduction}

It is well established that oral glucose tolerance is frequently worse in the afternoon or evening than in the morning in apparently healthy subjects (Roberts, 1964; Bowen and Reeves, 1967; Jarrett and Keen, 1969, 1970; Jarrett et al., 1972; Carrol and Nestel, 1973). This deterioration of glucose tolerance later in the day is usually associated with an impaired insulin response (Jarrett et al., 1972; Carrol and Nestel, 1973). The phenomenon of diurnal variation of glucose tolerance and insulin response to glucose ingestion in subjects with diabetes mellitus has, however, received relatively little attention. The occurrence of such a diurnal rhythm could conceivably have practical implications, particularly in relation to management of diabetes. We have investigated this subject and present here the results of such a study in twenty patients with recently diagnosed diabetes mellitus.

\section{Patients and methods}

Twenty subjects who had been referred to the Diabetic Clinic were investigated as outpatients. Diabetes was diagnosed on the basis of a random capillary blood sugar of over $180 \mathrm{mg} / 100 \mathrm{ml}$ in association with glycosuria and symptoms of diabetes. None of the patients had ketonuria. Their symptoms were sufficiently mild to justify postponement of treatment until they had participated in this study. The patients were chosen purely on the basis of willingness to participate in this study. Six were

Correspondence: Dr C. H. Walsh, The General Hospital, Steelhouse Lane, Birmingham B4 6NH. female (mean age 62 years; age range 53-68 years) and fourteen male (mean age 52 years; age range 39-76 years). Each subject had two glucose tolerance tests, one in the morning and one in the evening. The tests were carried out under standardized conditions and in random order. The morning test began at 9 a.m. and the evening test between 4.30 and 5 p.m. The interval between the tests ranged from 2 to 6 days. The subjects fasted for between 8.5 to 9 $\mathrm{hr}$ before each test. In addition, all subjects took a light meal of approximately equal caloric value just before the start of each fasting period. No subject was on any treatment known to interfere with carbohydrate metabolism and all subjects continued on unrestricted diet while participating in the study.

Two-hour glucose tolerance tests were carried out using $50 \mathrm{~g}$ glucose (as 'Lucozade'). Venous blood glucose was measured by the Auto-analyser ferricyanide method, the samples being collected in tubes containing fluoride-oxalate. Blood glucose estimations from the morning test were carried out on the same day. For the evening tests the samples were stored and the blood glucose estimations were carried out on the following morning. For insulin measurements, the serum was separated and stored at $-20^{\circ} \mathrm{C}$. Serum immuno-reactive insulin was measured by the double antibody technique. The anti-insulin antiserum, the human insulin standard and the antiguinea-pig precipitating serum were obtained from Wellcome Laboratories. The $\mathbf{I}^{\mathbf{1 2 5}}$-labelled insulin was obtained from the Radiochemical Centre, Amersham. All insulin measurements from each individual were carried out in a single assay.

\section{Statistical analysis}

The significance of the differences between the paired glucose tolerance test results was tested using Student's $t$ test. In addition the increments in blood glucose at the different points after glucose loading in the morning and afternoon were compared.

\section{Results}

\section{Glucose tolerance tests}

The results for the twenty subjects are seen in Table 1. The overall trend is for the blood glucose values to be higher in the morning than in the after- 
TABLE 1. (a) Mean blood glucose values $(\mathrm{mg} / 100 \mathrm{ml}$ ) for twenty subjects and (b) mean serum insulin values $(\mu \mathrm{u} / 100 \mathrm{ml})$ for nineteen subjects $( \pm$ s.d. of the mean $)$

\begin{tabular}{|c|c|c|c|c|c|c|c|c|c|c|}
\hline \multirow[b]{2}{*}{ Time of test } & \multicolumn{10}{|c|}{ Time (min) } \\
\hline & \multicolumn{2}{|r|}{0} & \multicolumn{2}{|r|}{30} & \multicolumn{2}{|r|}{60} & \multicolumn{2}{|r|}{90} & \multicolumn{2}{|r|}{120} \\
\hline (a) & & & & & & & & & & \\
\hline $\begin{array}{l}\text { a.m. } \\
\text { p.m. }\end{array}$ & $\begin{array}{l}214 \\
154\end{array}$ & $\begin{array}{l}(66 \cdot 46) \\
(50 \cdot 6)\end{array}$ & $\begin{array}{l}281 \\
224\end{array}$ & $\begin{array}{l}(69 \cdot 7) \\
(54 \cdot 05)\end{array}$ & $\begin{array}{l}320 \\
295\end{array}$ & $\begin{array}{l}(67 \cdot 4) \\
(62 \cdot 5)\end{array}$ & $\begin{array}{l}299 \\
280\end{array}$ & $\begin{array}{l}(74 \cdot 74) \\
(80 \cdot 6)\end{array}$ & $\begin{array}{l}278 \\
255\end{array}$ & $\begin{array}{l}(78 \cdot 7) \\
(55 \cdot 22)\end{array}$ \\
\hline \multicolumn{11}{|l|}{ (b) } \\
\hline $\begin{array}{l}\text { a.m. } \\
\text { p.m. }\end{array}$ & $\begin{array}{l}14 \\
13 \cdot 6\end{array}$ & $\begin{array}{l}(5 \cdot 4) \\
(4 \cdot 04)\end{array}$ & $\begin{array}{l}18 \cdot 4 \\
21 \cdot 4\end{array}$ & $\begin{array}{l}(8.04) \\
(11 \cdot 3)\end{array}$ & $\begin{array}{l}23 \cdot 0 \\
25 \cdot 1\end{array}$ & $\begin{array}{l}(13 \cdot 29) \\
(14 \cdot 96)\end{array}$ & $\begin{array}{l}23 \cdot 2 \\
25 \cdot 3\end{array}$ & $\begin{array}{l}(16 \cdot 25) \\
(18 \cdot 53)\end{array}$ & $21 \cdot$ & $\begin{array}{r}(12 \cdot 84) \\
5(12 \cdot 76)\end{array}$ \\
\hline
\end{tabular}

TABLE 2. Mean blood glucose values $(\mathrm{mg} / 100 \mathrm{ml})$ for $(\mathrm{a})$ the subjects who are more than $10 \%$ in excess of ideal body weight and (b) the subjects within $10 \%$ of ideal body weight ( \pm s.d. of the mean)

\begin{tabular}{|c|c|c|c|c|c|}
\hline Time of test & 0 & 30 & $\begin{array}{c}\text { Time }(\mathrm{min}) \\
60\end{array}$ & 90 & 120 \\
\hline \multicolumn{6}{|l|}{ (a) } \\
\hline a.m. & $196(63 \cdot 32)$ & $276(75 \cdot 29)$ & $311(79 \cdot 58)$ & $277(85 \cdot 42)$ & $251(87 \cdot 9)$ \\
\hline p.m. & $152(39 \cdot 01)$ & $220(48 \cdot 63)$ & $297(70 \cdot 81)$ & $278(58.05)$ & $245(54 \cdot 18)$ \\
\hline Statistical significance & $P<0.0025$ & $P<0.05$ & & & \\
\hline \multicolumn{6}{|l|}{ (b) } \\
\hline a.m. & $198(66 \cdot 09)$ & $285(69 \cdot 02)$ & $326(60.95)$ & $314(66 \cdot 23)$ & $288(69 \cdot 57)$ \\
\hline p.m. & $157(58 \cdot 86)$ & $233(56 \cdot 0)$ & $293(57 \cdot 72)$ & $296(61 \cdot 11)$ & $261(56 \cdot 13)$ \\
\hline Statistical significance & $P<0.0025$ & $P<0.0005$ & $P<0.01$ & & $P<0.0025$ \\
\hline
\end{tabular}

noon. The differences between the morning and afternoon values are statistically significant in the fasting state $(P<0.001), 30 \mathrm{~min}$ after glucose ingestion $(P<0.001)$ and $120 \mathrm{~min}$ after glucose ingestion $(P<0.025)$.

In order to determine whether the degree of hyperglycaemia might influence the results, the subjects were divided into two groups using a fasting morning blood glucose of $150 \mathrm{mg} / 100 \mathrm{ml}$ as an arbitrary dividing line. Those with a fasting blood glucose of over $150 \mathrm{mg} / 100 \mathrm{ml}$ have been called 'severely' hyperglycaemic while those with a fasting blood glucose of under $150 \mathrm{mg} / 100 \mathrm{ml}$ have been called 'moderately' hyperglycaemic. The results for these groups are seen in Figs. 1 and 2. The results for the 'severely' hyperglycaemic group differ significantly while fasting $(P<0.0005)$, and at $30 \mathrm{~min}(P<0.0005)$, $60 \mathrm{~min}(P<0.025)$ and $120 \mathrm{~min}(P<0.005)$ after glucose. Though the 'moderately' hyperglycaemic group has a significantly higher fasting blood glucose in the morning $(P<0.01)$ the post-glucose values do not differ significantly in the morning and afternoon.

The effect of excessive body weight was determined by dividing the subjects into those who weighed more than $10 \%$ in excess of their ideal body weight (eight subjects) and those who weighed within $10 \%$ of their ideal body weight (twelve subjects). The results are shown in Table 2. The differences between the morning and afternoon tests are more striking in the patients who are closer to their ideal body weight.

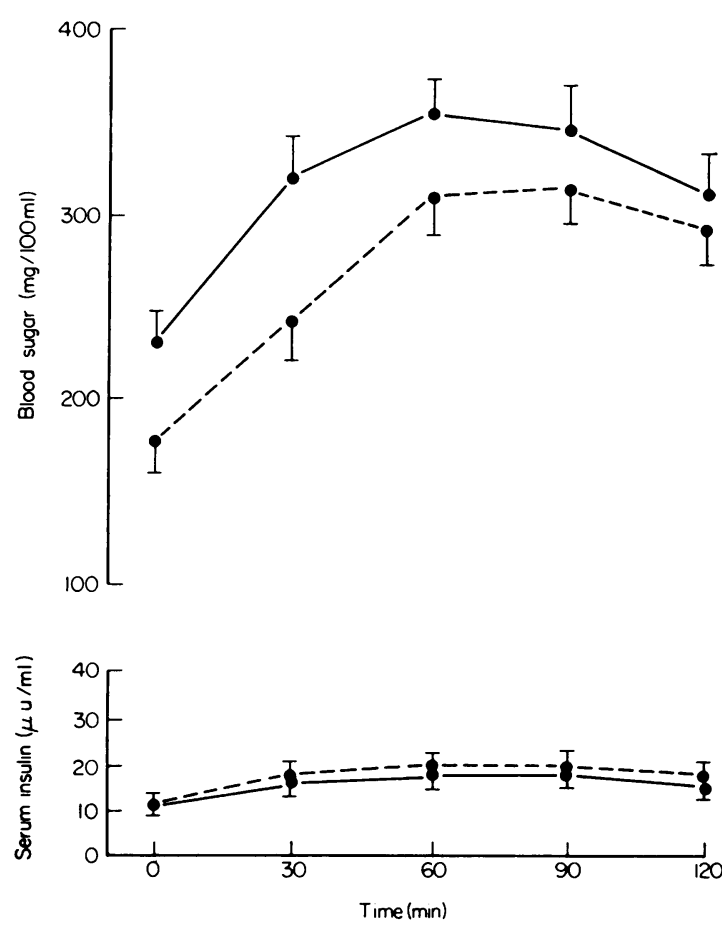

Fig. 1. Mean blood glucose levels (thirteen subjects) and serum insulin levels (thirteen subjects) for the 'severely' hyperglycaemie subjects. Solid line, a.m.; dashed line, p m. 

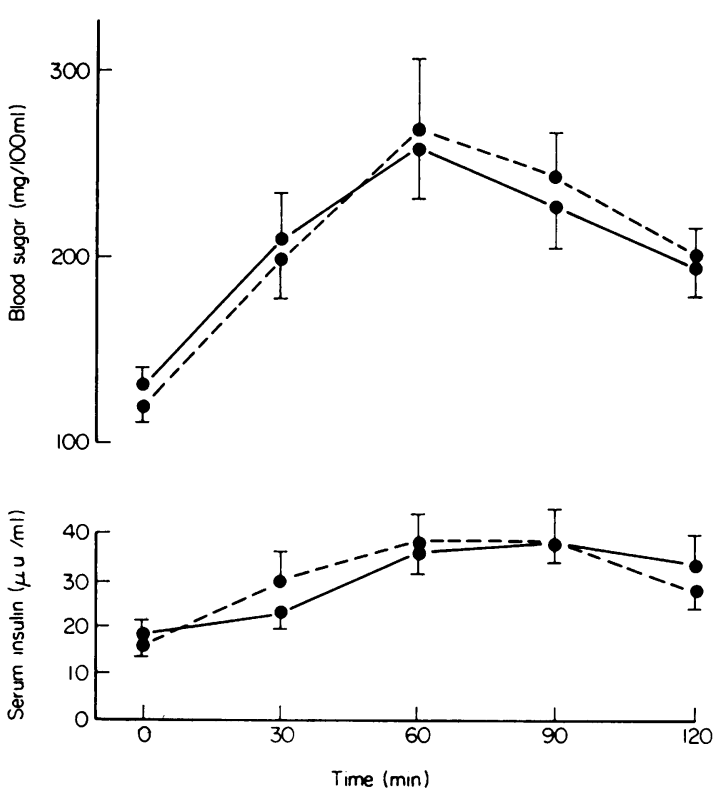

Fig. 2. Mean blood glucose levels (seven subjects) and mean serum insulin levels (six subjects) for the 'moderately' hyperglycaemic subjects. Solid line, a.m.; dashed line, p.m.

The results for the men (fourteen subjects) and women (six subjects) were analysed separately. The results can be seen in Table 3 . The differences between the morning and afternoon values are greater in the female group.

The increments in blood glucose at the various times after glucose ingestion (i.e. 30, 60, 90 and 120 min) were examined for the different groups, and the morning and afternoon values compared. In no case did the morning values significantly exceed the corresponding afternoon values.

The mean per cent above ideal body weight for the 'severely' and 'moderately' hyperglycaemic groups did not differ significantly. Likewise there was no significant difference between the male and female groups.

\section{Serum insulin results}

The mean serum insulin values for nineteen subjects are seen in Table 1. The results are almost identical in both the morning and afternoon. Likewise, there was no significant diurnal variation in insulin values when the patients were divided according to degree of hyperglycaemia (Figs 1 and 2), weight or sex.

\section{Discussion}

The results of this study indicate that the blood glucose values both in the basal state and after glucose ingestion tend to be higher in the morning than later in the day in many diabetics. The higher values in the morning after glucose ingestion are related to the occurrence of higher basal values at this time. The glucose tolerance curve for the whole group and particularly for the 'severely' hyperglycaemic group is higher at all points in the morning than later in the day, but the incremental rise in blood glucose after glucose ingestion is not significantly greater in the morning so that 'glucose tolerance' is no worse in the morning than the afternoon. It has long been recognized that there exists in many diabetics a diurnal rhythm of the blood sugar with the highest levels occurring in the morning (Hatlehol, 1924; Izzo, 1947; Faiman and Moorhouse, 1967). This pattern is also found in many treated diabetics (Rigas et al. 1968). It is only in recent years, however, that diurnal variations in glucose tolerance have been studied in diabetic patients. Jarrett and Keen $(1969,1970)$ performed morning and afternoon glucose tolerance tests in a number of subjects with varying degrees of hyperglycaemia. They found that in subjects with 'border-line' hyperglycaemia the response to a glucose load was significantly worse in the afternoon. As the degree of hyperglycaemia increased, however, the difference between the morning and afternoon glucose tolerance became insignificant.

The results of this study agree with the results of other workers (Jarrett and Keen, 1969, 1970) only in that the morning fasting blood glucose level tends to be higher than the corresponding afternoon value.

TABLE 3. Mean blood glucose values $(\mathrm{mg} / 100 \mathrm{ml}) \pm \mathrm{s} . d$. of the mean, for (a) men and (b) women

\begin{tabular}{|c|c|c|c|c|c|}
\hline \multirow[b]{2}{*}{ Time of test } & \multicolumn{5}{|c|}{ Time (min) } \\
\hline & 0 & 30 & 60 & 90 & 120 \\
\hline \multicolumn{6}{|l|}{ (a) } \\
\hline a.m. & $\begin{array}{l}198(65 \cdot 63) \\
161(57 \cdot 41)\end{array}$ & $\begin{array}{ll}273 & (74 \cdot 92) \\
231 & (58 \cdot 92)\end{array}$ & $\begin{array}{ll}301 & (67 \cdot 09) \\
301 & (70 \cdot 44)\end{array}$ & $\begin{array}{l}288(72 \cdot 75) \\
292(66 \cdot 82)\end{array}$ & $\begin{array}{ll}269 & (80.46) \\
253 & (61 \cdot 0)\end{array}$ \\
\hline Significance & $P<0.0005$ & $P<0.005$ & & & \\
\hline \multicolumn{6}{|l|}{ (b) } \\
\hline $\begin{array}{l}\text { a.m. } \\
\text { p.m. }\end{array}$ & $\begin{array}{l}195(63 \cdot 35) \\
137(26 \cdot 71)\end{array}$ & $\begin{array}{l}300(60 \cdot 15) \\
221(35 \cdot 32)\end{array}$ & $\begin{array}{l}347(55 \cdot 32) \\
274(39 \cdot 10)\end{array}$ & $\begin{array}{l}325(78.95) \\
281(39.37)\end{array}$ & $\begin{array}{ll}287 & (81 \cdot 4) \\
258 & (43 \cdot 54)\end{array}$ \\
\hline Significance & $P<0.01$ & $P<0.01$ & $P<0.0025$ & $P<0.05$ & \\
\hline
\end{tabular}


In contrast to us, these workers failed to find significantly higher values in the morning after glucose ingestion. There are at least two reasons for this apparent conflict. Firstly, it has been shown that in older subjects glucose tolerance tends to deteriorate as the pre-test fasting period is shortened (Walsh, O'Regan and O'Sullivan, 1973). In previous investigations (Jarrett and Keen, 1969, 1970) the fasting period before the afternoon test was shorter (by a minimum of $90 \mathrm{~min}$ ) than that before the morning test. This may have resulted in a greater degree of impairment of glucose tolerance in the afternoon than would have occurred under more standardized conditions. Secondly, and probably more important, is the fact that the patients in our study were considerably more hyperglycaemic than most of those investigated previously. It appears that many of the individuals investigated in former studies had hyperglycaemia of the same degree, or even milder, than our 'moderately' hyperglycaemic patients. In this context it is interesting that it is in our patients with 'severe' hyperglycaemia that the differences between the morning and afternoon blood glucose values are more striking. While this may indicate that the degree of diurnal variation of blood glucose in diabetics is related to the degree of hyperglycaemia, we cannot draw a definite conclusion on this point because of the small numbers studied. When our patients are divided into groups according to weight and sex, it appears that this diurnal pattern is more marked in patients within $10 \%$ of their ideal body weight than in those who exceed this and it is also more marked in female than in male diabetics. Again, however, because the numbers are small further studies will be needed to clarify these points.

The present work supports the hypothesis of Jarrett and Keen (1970) in relation to the development of diabetes. They suggested that afternoon hyperglycaemia is the first stage in the development of glucose intolerance. This is associated with impairment of insulin secretion (Jarrett et al., 1972; Carrol and Nestel, 1973). The next stage is the development of morning hyperglycaemia with loss of diurnal variation of glucose tolerance. Our results suggest that at this stage there is also a loss of diurnal rhythm of insulin secretion. Our results also suggest that the next stage in the development of florid diabetes is a further progressive rise in blood glucose levels in the morning. It is not possible on the basis of the present results to explain this progressive morning hyperglycaemia. It is conceivable, however, that the peak levels of cortisol which normally occur in the morning may, by causing insulin resistance, account at least in part for this phenomenon.

From a practical point of view, the results of this study have important implications in relation to the management of diabetics, particularly as outpatients (Walsh, Twomey and O'Sullivan, 1974). If the blood sugar is undesirably high when the patient attends a morning clinic, hypoglycaemic therapy may be increased. In the case of patients on a long-acting insulin preparation (or a long-acting sulphonylurea) this may lead to hypoglycaemia later in the day. On the other hand, if the blood sugar is thought to be at an acceptable level when the patient attends an afternoon clinic, diabetic control may be deemed to be satisfactory. This overlooks the fact that the blood glucose may have been undesirably high for some hours in the morning. It is possible that such short periods of poor diabetic control may, over a period of years, be of significance in relation to the development of diabetic complications.

\section{Acknowledgments}

We are grateful to Professor J. M. Malins and Dr M. G. FitzGerald for their helpful criticism of this work.

\section{References}

Bowen, A.J. \& ReEves, R.L. (1967) Diurnal variation in glucose tolerance. Archives of Internal Medicine, 119, 261.

Carrol, K.F. \& Nestel, P.J. (1973) Diurnal variation in glucose tolerance and in insulin secretion in man. Diabetes, 22, 333.

Faiman, C. \& Moorhouse, J.A. (1967) Diurnal variation in the levels of glucose and related substances in healthy and diabetic subjects during starvation. Clinical Science, 32, 111.

Hatlehol, R. (1924) Blood sugar studies; with special regard to the threshold of glycosuria in diabetes mellitus and benign chronic glycosuria. Acta medica scandinavica, suppl. viii, 1.

Izzo, J.L. (1947) Diurnal (24 hour) rhythm in diabetes mellitus; diurnal variations in levels of glucose in blood and urine. Proceedings of the American Diabetes Association, 9, 247.

JARRETT, R.J., BAKER, I.A., KeEN, H. \& OAKLEY, N.W. (1972) Diurnal variation in oral glucose tolerance: Blood sugar and plasma insulin levels in the morning, afternoon and evening. British Medical Journal, i, 199.

JARRETT, R.J. \& KEEN, H. (1969) Diurnal variation of oral glucose tolerance; a possible pointer to the evolution of diabetes mellitus. British Medical Journal, ii, 341.

JARRETT, R.J. \& KeEN, H. (1970) Further observations on the diurnal variation in oral glucose tolerance. British Medical Journal, iv, 334.

Rigas, A.N., Bittles, A.H., Hadden, D.R. \& MontGOMERY, D.A.D. (1968) Circadian variations of glucose, insulin and free fatty acids during long term use of oral hypoglycaemic agents in diabetes mellitus. British Medical Journal, iv, 25.

ROBERTS, H.J. (1964) Afternoon glucose tolerance testing; a key to the pathogenesis, early diagnosis and prognosis of diabetogenic hyperinsulinism. Journal of the American Geriatric Society, 12, 423.

Walsh, C.H., O'Regan, J. \& O'Sullivan, D.J. (1973) Effect of different periods of fasting on oral glucose tolerance. British Medical Journal, ii, 691.

Walsh, C.H., TwOMEY, C. \& O'Sullivan, D.J. (1974) Diurnal blood sugar patterns in treated diabetics. Irish Journal of Medical Science, 143, 155. 